\title{
Comparison of the safety and efficacy of ivabradine and nebivolol mono- and combination-therapies in the treatment of stable angina pectoris patients with left ventricular dysfunction
}

\author{
Rasim Kutlu'1, Mehmet Erdem Memetoglu² and Tolkun Murataliev Muratalievic3 \\ Department of ${ }^{1}$ Cardiology, ${ }^{2}$ Cardiovascular Surgery, Gümüshane State Hospital, Gümüshane, Turkey; \\ ${ }^{3}$ Department of Cardiology, National Cardiology and Internal Medicine Institude, Bishkek, Kyrgyzstan.
}

\begin{tabular}{|c|c|}
\hline \multicolumn{2}{|l|}{ Article Info } \\
\hline Received: & 28 May 2013 \\
\hline Accepted: & 7 June 2013 \\
\hline Available Online: & 19 June 2013 \\
\hline \multicolumn{2}{|c|}{ DOI: 10.3329/bjp.v8i3.15118 } \\
\hline \multicolumn{2}{|l|}{ Cite this article: } \\
\hline $\begin{array}{l}\text { Kutlu R, Meme } \\
\text { talievic TM. Comp } \\
\text { and efficacy of iva } \\
\text { olol mono- an } \\
\text { therapies in the } t \\
\text { angina pectoris } \\
\text { ventricular dysfun } \\
\text { Pharmacol. 2013; } 8\end{array}$ & $\begin{array}{l}\text { ME, Mura- } \\
\text { of the safety } \\
\text { ne and nebiv- } \\
\text { ombination- } \\
\text { lent of stable } \\
\text { ts with left } \\
\text { Bangladesh J } \\
\text { 1. }\end{array}$ \\
\hline
\end{tabular}

\begin{abstract}
We aimed to investigate the pharmacoeconomic efficacy of ivabradine and nebivolol in treatment of stable angina pectoris patients with left ventricular dysfunction prospectively. Pharmacoeconomic analysis was performed by using cost minimization analysis, and cost effectiveness analysis. After 6 months' treatment LVEF for the nebivolol group (17 patients, 50\%) improved by $(38 \pm 6.5)$ to $(41 \pm 3.2),(\mathrm{p}>0.05)$ and for the ivabradine group (17 patients, $50 \%)(37 \pm 5.4)$ to $(41 \pm 2.3),(p>0.05)$, mean MET value in the nebivolol group increased from $(3.7 \pm 1.2)$ to $(5.5 \pm 1.6),(\mathrm{p}>0.05)$, versus from $(3.6 \pm 1.5)$ to $(5.5$ $\pm 1.4),(p>0.05)$ in the ivabradine group, cost minimization analysis results showed a difference in the total cost of treatment was US\$ 5288.7 in favor of nebivolol. The findings suggest that nebivolol is more cost-effective than ivabradine in the treatment of patients with left ventricular dysfunction.
\end{abstract}

\section{Introduction}

Atherosclerotic coronary artery disease is a chronic disease that progresses insidiously throughout a person's lifespan, being generally at an already-advanced stage at the time its symptoms become first manifest. Coronary artery disease often assumes a further compli -cated state, such as acute coronary syndrome, that can trigger patient mortality. In recent times, coronary artery disease mortality has decreased significantly in many European countries. However, $>80 \%$ of all coronary artery disease deaths in our day occurs in developing countries.

Stable angina pectoris is a clinical condition that is frequently encountered with coronary artery disease. New tools are currently being developed for the diagnosis and prognosis of patients with stable angina pectoris. In addition to this, databases pertaining to stable angina pectoris treatment strategies are constantly evolving. This situation necessitates an update of the existing treatment strategies (Arrebola-Moreno et al., 2011). It has been shown that mortality in chronic heart failure patients may increase in relation to an elevated heart rate. With regards to chronic heart failure mortality, it has been observed that an increase in heart rate of 1 beat per minute increases the mortality risk by $3 \%$, while an increase in heart rate of 5 beats per minute increases the mortality risk by 16\% (Borer et al., 2012; Swedberg et al., 2010).

Ivabradine inhibits the pacemaker If current by slowing the diastolic depolarization slope in sinoatrial node cells in a dose-dependent fashion. When the available data regarding ivabradine is examined, it can be seen that ivabradine has the potential to slow-down the development of aterosclerosis, correct ischemia, and reduce the frequency of angina attacks, the prevalence of fatal and non-fatal myocardial infarction, and the rate patient hospitalization due to the said conditions (Borer et al., 2012; Swedberg et al., 2010; Kim et al., 2008). The results of the BEAUTIFUL study (Kim et al., 2008) have 
demonstrated that ivabradine is a good choice for antianginal and antiischemic treatment, that it reduced the incidence of myocardial infarction and the need for coronary revascularization, and that it has a good tolerability profile when used in combination with other drugs. This study has also shown that ivabradine use represents an advancement in the treatment of stable angina pectoris patients with heart rates $\geq 70$ beats per minute, and that the isolated decrease in heart rate caused by ivabradine decreased the occurrence of coronary events even in patients already receiving optimal cardiovascular protective therapies.

The efficacy of beta-blockers in treatment coronary artery disease and stable angina pectoris patients is established in the current guidelines (Tatarchenko et al., 2008; Tardif et al., 2009). Among the different betablockers, nebivolol is a cardioselective agent that has long-term efficacy.

To the best of our knowledge, our study is the first to comparatively evaluate mono- and combination therapies of nebivolol and ivabradine as well as the early and six month late period efficacy of these drugs in stable angina pectoris patients with left ventricular ejection fractions (LVEFs) $\leq 40 \%$.

\section{Materials and Methods}

The study was approved by the local ethics committee. A total of 50 stable angina pectoris patients under follow-up in our cardiology department with LVEFs $\leq 40 \%$ were included into the study. The patient distribution according to gender was 21 male patients and 29 female patients (Table I). The age average was determined as $61 \pm 5.1$.

The patients were evaluated in 3 different groups (A, B, C). Only nebivolol was administered to the 17 patients included in Group A. Seventeen patients who could not

\begin{tabular}{|lccc|}
\hline \multicolumn{4}{c|}{ Table I } \\
Risk factors \\
\hline Risk Factors & $\begin{array}{c}\text { Group A } \\
\text { (n= 17) }\end{array}$ & $\begin{array}{c}\text { Group B } \\
(\mathrm{n}=17)\end{array}$ & $\begin{array}{c}\text { Group C } \\
(\mathrm{n}=16)\end{array}$ \\
\hline Male & 8 & 7 & 6 \\
Female & 9 & 10 & 10 \\
Tip II Diabetes & 8 & 6 & 9 \\
Genetic predisposi- & 8 & 9 & 7 \\
tion & & & \\
Smoking & 9 & 8 & 11 \\
Psychosocial factors & 13 & 14 & 12 \\
Dyslipidemia & 11 & 14 & 15 \\
Obesity & 15 & 16 & 14 \\
Abdominal obesity & 16 & 17 & 15 \\
Hypertension & 16 & 17 & 16 \\
\hline
\end{tabular}

tolerate nebivolol (due to COPD, bronchospasm, bronchial asthma, erectile dysfunction, asthenia, insomnia, coronary vasoconstriction, hypotension, and/or allergic reaction to active molecule) were started on ivabradine treatment, and these patients were included into group B. In group C, ivabradine and nebivolol were administered in combination to 16 patients who developed nebivolol intolerance and/or who could not achieve effective treatment despite separate nebivolol and ivabradine administration at the highest dose. The daily starting dose for ivabradine and nebivolol treatment was determined and administered by titration. The starting dose for ivabradine was initially determined as $5 \mathrm{mg} /$ day (administered twice daily), which was later increased to an average of $10 \mathrm{mg} /$ day, and to a maximum dose of $15 \mathrm{mg} /$ day for patients in which treatment effectiveness could not be achieved. The starting dose for nebivolol treatment was initially 2.5 $\mathrm{mg} /$ day (administered one daily), which was then continued at an average of $5 \mathrm{mg} /$ day. For two patients included in group A with whom optimal treatment effectiveness could not be achieved, the dose was increased up to a maximum of $10 \mathrm{mg} /$ day. For group $\mathrm{A}$, the average daily dose for patients using nebivolol was $6 \pm 1.6 \mathrm{mg} /$ day; for group $B$, the average ivabradine dose was $12 \pm 2.5 \mathrm{mg} /$ day; for group $\mathrm{C}$, the average ivabradine dose was $10 \pm 1.9 \mathrm{mg} /$ day, and the average nebivolol dose was $4 \pm 1.2 \mathrm{mg} /$ day. In addition to this, the average hospitalization periods of the patients included into the study were calculated in order to assess drug efficacy.

Stable angina pectoris was diagnosed according to the ESC (Fraker et al., 2007) and ACC/AHA (Amosova et al., 2011) cardiology guidelines. According to the study criteria, patients with LVEF equal to or below $40 \%$ were included into our study. Forty nine patients were diagnosed with hypertension according to the World Health Organization Hypertension Association (WHOHA). Seventeen patients were diagnosed with COPD according to the Global Initiative for Chronic Obstructive Lung Disease (GOLD, 2009).

The Seattle stable angina pectoris quality of life questionnaire (Seattle Angina Questionnaire - SAQ) was used to assess the quality of life of the patients included into the study. This questionnaire, which is constituted of five categories, was completed twice by the patients during the study, first before the beginning of treatment, and once again 6 months later, to measure the dynamic slope. The questionnaire respectively evaluated the physical limitation (PL), angina stability (AS), angina frequency (AF), treatment satisfaction (TS) and disease perception (DP) of the patients. When performing calculations for the questionnaire, whose questions were each scored between 1 and 6, the following formulas were used: $\mathrm{PL}=100 \% \times(\mathrm{Q} 1+\mathrm{Q} 2+$ $\mathrm{Q} 3+\mathrm{Q} 4+\mathrm{Q} 5+\mathrm{Q} 6+\mathrm{Q} 7+\mathrm{Q} 8+\mathrm{Q} 9-9) / 45$. 
$\mathrm{AS}=100 \% \times(\mathrm{Q} 10-1) / 4 . \mathrm{AF}=100 \% \times(\mathrm{Q} 11+\mathrm{Q} 12-2) / 10$.

$\mathrm{TS}=25 \% \times(\mathrm{Q} 13-1) / 5+75 \% \times(\mathrm{Q} 14+\mathrm{Q} 15+\mathrm{Q} 16-$ 3)/12.

$\mathrm{DP}=100 \% \times(\mathrm{Q} 17+\mathrm{Q} 18+\mathrm{Q} 19-3) / 12$.

Each section was calculated on the basis of percentages (\%). As result, an average of $0 \%$ was considered as poor, an average of $50 \%$ was considered as moderate, and an average of $100 \%$ was considered as good. The patients' follow-ups were performed for a period of six months, with their examinations being performed at the polyclinic on a monthly basis. The patients' blood pressure (with WHO-HA values being taken as reference), heart rate and body mass index (BMI) (kg/ $\mathrm{m}^{2}$ ) were measured at each visit. The BMI reference values were such that values $<18.5$ were considered as underweight, values between 18.5-24.9 as normal weight (healthy), values between 25-29.9 as overweight, and values $\geq 30$ as obese. The patients' waist circumference values were also measured. The reference values for waist circumference were $102 \mathrm{~cm}$ for males, and $88 \mathrm{~cm}$ for females. During the control examinations, full blood count, urinalysis, AST, ALT, lipid values and fasting blood sugar values of all patients were also evaluated. As test, standard 12-Lead Electrocardiographies (ECGs) were performed (all evaluated patients had sinus rhythm). Transthoracic echocardiography $(\mathrm{ECHO})$ and ejection fraction were measured with the Simpson method $(\mathrm{EF}=$ left ventricle end diastolic diameter - left ventricle end systolic diameter/left ventricle end diastolic diameter $x 100 \%)$. For the measurement of diastolic function, the following normal diastolic index parameters were taken as average references: E/A: $1.3 \pm 0.4$, IVRT: $63 \pm 1.4 \mathrm{~m} / \mathrm{s}$, Deceleration time: 150-200 ms, P. vein Ar-A: $28 \pm 6 \mathrm{~ms}$, Em/Am: $2.1 \pm 0.9$. In addition to this, left ventricle diastolic dysfunction was staged as I, II, III or IV. The Duke Treadmill Score (DTS) was measured for patients performing the effort test. The formula for DTS is: [exercise period (minutes) - $15 \times$ ST deviation] - [4 $\mathrm{x}$ angina index (angina index: 0 - angina; 1 - limited angina; 2 - test stopping angina)]. Reference values were accepted as follows: -11 and below were considered as high risk, -10 to +4 as moderate risk, +5 and above as low risk. Based on the NHYA classification, the metabolic equivalent of task (MET) of the patients were categorized as follows: MET $\geq 7$ was considered as class I, MET $\leq 5$ as class II, MET $\leq 2$ as class III, and MET $\leq 1$ as class IV.

Spirometry and peak flow meter monitoring were performed to measure pulmonary function. To measure the patients' renal function, the pre-treatment and sixth month post-treatment proteinuria $(\mathrm{mg} / \mathrm{g})$, microalbuminuria $(\mathrm{mg} / \mathrm{g})$, creatinine and glomerular filtration rates (GFR) were recorded. For the GFD measurements, the following MDRD formula was used: GFD (mL/ $\min )=1.9 \times($ serum creatinine $)-1.2 \times($ age $)-0.2 \times(0.7$ for women).

Transthoracic echocardiography (ECHO) were performed with the Philips HD11XE device (Philips Medical Systems, Bothell, WA, USA), and the effort tests were performed with the Tepa Tm-Pro-2000 device (TM-PRO 2000, Tepa, Turkey).

\section{Statistical analysis}

All obtained statistical data were analyzed with "Statistica 10 " programs. Non-parametric criteria were employed for intergroup statistical comparisons. The Wilcoxon matched pairs rank test was used to determine whether the intergroup differences were statistically significant, the Mann-Whitney " $U$ " and " $T$ " tests were used to determine independent values, and the Pearson (r) product-moment criteria was used for the measurement of the correlation coefficient.

\section{Results}

The patients were administered a diet for hypertension, hyperlipidemia and hyperglycemia. There were no changes in the levels of obesity and abdominal obesity during and after the study. Only 4 out of the 28 smoking patients informed that they had quitted smoking. The blood pressure values of patients with hypertension decreased to normal levels during and at the end of the treatment. The average post-treatment systolic and diastolic blood pressure values between the groups were measured as $128 \pm 2.4$ and $85 \pm 3.5$ for Group A, $129 \pm 1.8$ and $88 \pm 3.2$ for Group B, $126 \pm 1.0$ and $82 \pm 1.2$ for Group C. For the 23 patients with type II diabetes, the average post-treatment $\mathrm{HbA1c}$ value was measured as $6.7 \pm 1.2 \%$. For the $40(80 \%)$ with dyslipidemia, the average post-treatment LDL value was determined as $101 \pm 2.3 \mathrm{mg} / \mathrm{dL}$.

A comparative table of the medications used by the patients during treatment, and the intergroup distribution of these medications is shown in Table II. At the end of the six month treatment, the number of patients using nitrates was determined as 4 for group A, 2 for group $B$, and 1 for group $C$. The number of patients using trimetazidine was determined as 1 for group A. No changes were observed in the trimetazidine-using 5 patients from group $B$ and the 3 patients from group $C$.

The pre-treatment clinical values of the patients were compared. According to this comparison, the intergroup average heart rate was determined as $87 \pm 2.1$ beats/min. The intergroup LVEF average was determined as $35 \pm 3.3$. The intergroup monthly angina attack average was identified as $15 \pm 1.1$. The intergroup DTS average was recorded as $-5 \pm 1.1$. The distribution of diastolic dysfunction stage, the stable angina pectoris distribution according to the Canadian 


\begin{tabular}{|l|r|r|r|}
\hline \multicolumn{4}{|c|}{ Table II } \\
\hline Medications used by the patients during treatment \\
\hline Medication & $\begin{array}{c}\text { Group A } \\
\text { (n = 17) }\end{array}$ & $\begin{array}{c}\text { Group B } \\
(\mathrm{n}=17)\end{array}$ & $\begin{array}{c}\text { Group C } \\
(\mathrm{n}=16)\end{array}$ \\
\hline Ivabradine & - & 17 & 16 \\
Nebivolol & 17 & - & 16 \\
Aspirin & 17 & 17 & 16 \\
Nitrate & 9 & 8 & 8 \\
Trimetazidine & 4 & 5 & 3 \\
Statin & 11 & 14 & 15 \\
Diuretic & 7 & 6 & 9 \\
Aldosterone antago- & 11 & 10 & 11 \\
nist & & & \\
ACE inhibitor & 16 & 13 & 16 \\
Diabetic medication & 8 & 6 & 9 \\
Calsium channel & 5 & 4 & 6 \\
blockers & & & \\
Cholinolytic inhala- & - & 11 & - \\
tion & & & \\
Corticosteriod inhala- & - & 6 & - \\
tion & & & \\
\hline
\end{tabular}

classification, the intergroup distribution of the COPD stages, the intergroup distribution of WHO HA stages between the patients, and the intergroup distribution of NYHA chronic heart failure classes are provided in Table III.

In Table IV, we have presented a comparison of the data and results of the Seattle stable angina pectoris quality of life questionnaire (SAQ), which we have used to assess the quality of life of the patients included into the study. These data include the pre-treatment initial results and the sixth month results. According to the results of the quality of life questionnaire, significant improvements were observed in each group, with the positive changes in Group C patients being more significant in comparison to the other groups.

The pre-treatment and sixth month LVEF values of the patients were compared (Figure 1). Improvement was identified in all patients groups.

It was observed that improvement was more significant in Group C (36-44\%), where ivabradine and nebivolol were administered in combination. An intergroup

\section{Table III}

\section{Comparison of the pre-treatment clinical and characteristic values of the patients}

\begin{tabular}{|c|c|c|c|c|}
\hline Values & $\begin{array}{c}\text { Group A } \\
(\mathrm{n}=17)\end{array}$ & $\begin{array}{c}\text { Group B } \\
(\mathrm{n}=17)\end{array}$ & $\begin{array}{c}\text { Group C } \\
(\mathrm{n}=16)\end{array}$ & $\mathrm{p}$ value \\
\hline Heart Rate (beats/min) & $86 \pm 4.1$ & $87 \pm 3.7$ & $89 \pm 5.2$ & $>0.05$ \\
\hline $\mathrm{EF}(\%)$ & $38 \pm 2.1$ & $37 \pm 3.2$ & $36 \pm 2.4$ & $>0.05$ \\
\hline DDF Stage I & 2 & 1 & 1 & $>0.05$ \\
\hline DDF Stage II & 6 & 7 & 5 & $>0.05$ \\
\hline DDF Stage III & 8 & 9 & 8 & $>0.05$ \\
\hline DDF Stage IV & - & - & 2 & - \\
\hline DTS (average) & $-6 \pm 4.2$ & $-4 \pm 3.1$ & $-4 \pm 3.4$ & $>0.05$ \\
\hline Monthly angina attacks & $13 \pm 5.1$ & $14 \pm 4.2$ & $18 \pm 3.1$ & - \\
\hline SAP Canadian Class I & 4 & 2 & 1 & $>0.05$ \\
\hline SAP Canadian Class II & 5 & 5 & 3 & $>0.05$ \\
\hline SAP Canadian Class III & 8 & 10 & 10 & $>0.05$ \\
\hline SAP Canadian Class IV & - & - & 2 & - \\
\hline COPD Stage I & - & 3 & - & - \\
\hline COPD Stage II & - & 12 & - & - \\
\hline COPD Stage III & - & 2 & - & - \\
\hline WHO-HA Stage I & 2 & - & 2 & - \\
\hline WHO-HA Stage II & 4 & 4 & 3 & $>0.05$ \\
\hline WHO-HA Stage III & 11 & 13 & 10 & $>0.05$ \\
\hline WHO-HA Stage IV & - & - & - & - \\
\hline NYHA CHF Class I & 3 & 2 & 1 & $>0.05$ \\
\hline NYHA CHF Class II & 5 & 4 & 3 & $>0.05$ \\
\hline NYHA CHF Class III & 9 & 11 & 10 & $>0.05$ \\
\hline NYHA CHF Class IV & - & - & 2 & - \\
\hline \multicolumn{5}{|c|}{$\begin{array}{l}\text { EF: Ejection fraction, COPD: Chronic Obstructive Pulmonary Disease, SAP: Stable angina pectoris, WHO: World Health Organization, CHF } \\
\text { Chronic Heart Failure, DDF: Diastolic dysfunction, DTS: Duke Treadmill Score. WHO-HA: World Health Organization Hypertansiyon Associa- } \\
\text { tion, NYHA: New York Heart Association }\end{array}$} \\
\hline
\end{tabular}




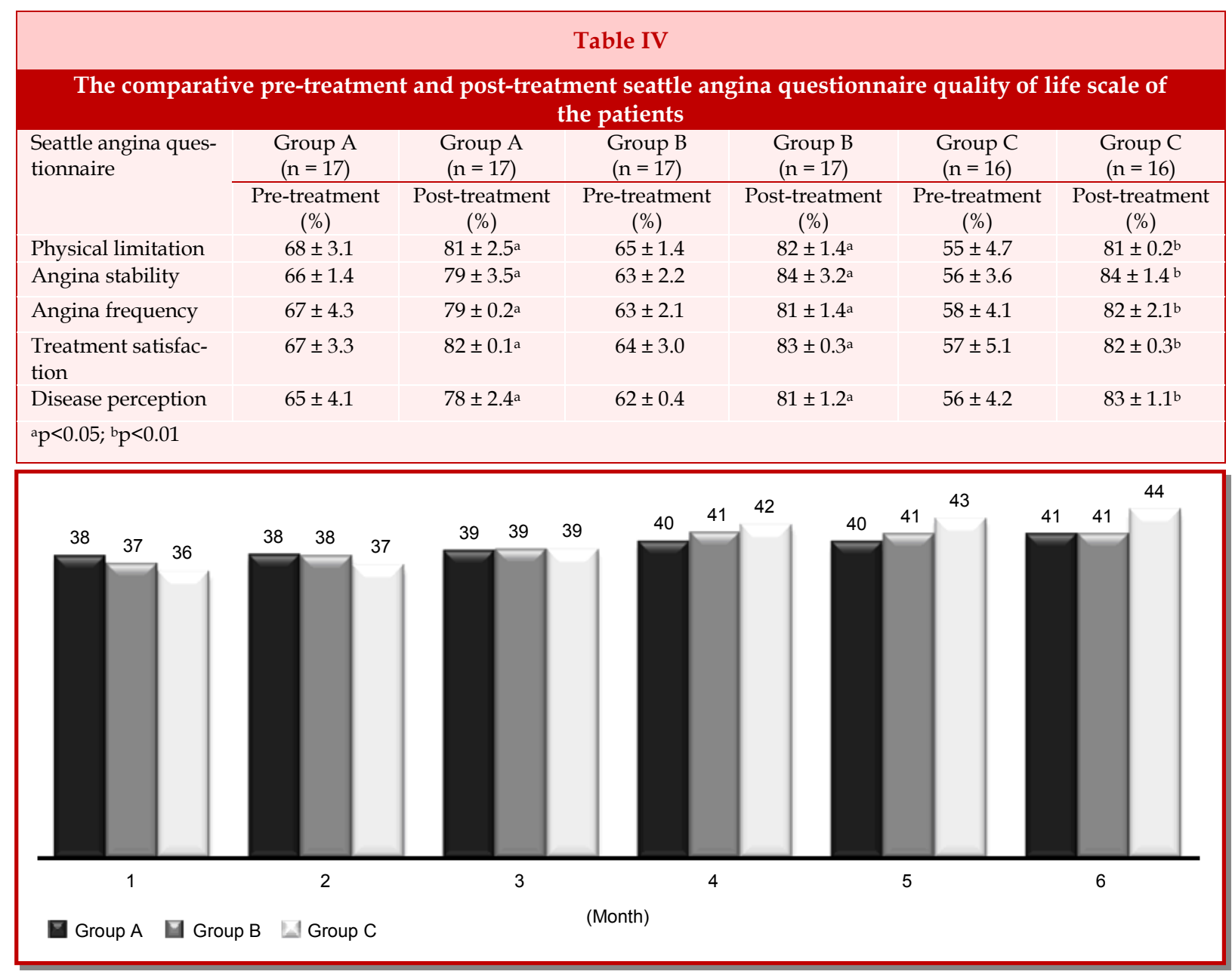

Figure 1: Intergroup comparison of pre-treatment and post-treatment ejection fraction. Data presented as percentage

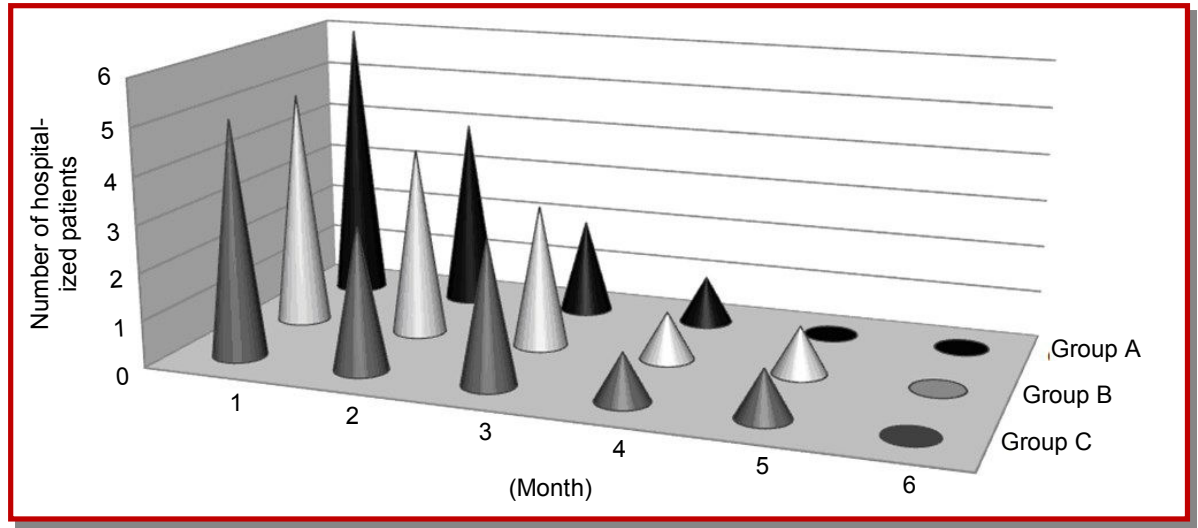

Figure 2: Comparative intergroup rates of hospitalization on a monthly basis. Data are presented as percentage

comparison of the rates of patient hospitalization was performed. A decrease in hospitalization was observed in each group (Figure 2).

While no significant changes were noted between Group A and B, a more significant change was observed in Group C patients, who were administered with the ivabradine and nebivolol combination. While no hospitalization was observed in Group C patients star- ting from the fourth month, absence of hospitalization was noted for Group A and B patients by the end of the fifth month.

A significant improvement in the diastolic indices was observed within the context of the pre-treatment and post-treatment intergroup comparisons (Table V). According to these comparisons, an equal level of improvement in diastolic function was observed in the 
Table V

The intergroup comparative averages of pre-treatment and post-treatment diastolic function parameters

\begin{tabular}{|c|c|c|c|c|c|c|}
\hline \multirow[t]{2}{*}{ Diastolic index } & $\begin{array}{l}\text { Group A } \\
(\mathrm{n}=17)\end{array}$ & $\begin{array}{c}\text { Group A } \\
(\mathrm{n}=17)\end{array}$ & $\begin{array}{l}\text { Group B } \\
(\mathrm{n}=17)\end{array}$ & $\begin{array}{l}\text { Group B } \\
(\mathrm{n}=17)\end{array}$ & $\begin{array}{l}\text { Group C } \\
(\mathrm{n}=16)\end{array}$ & $\begin{array}{l}\text { Group C } \\
(n=16)\end{array}$ \\
\hline & $\begin{array}{c}\text { Pre-treatment } \\
(\%)\end{array}$ & $\begin{array}{l}\text { Post-treatment } \\
(\%)\end{array}$ & $\begin{array}{l}\text { Pre-treatment } \\
(\%)\end{array}$ & $\begin{array}{l}\text { Post-treatment } \\
(\%)\end{array}$ & $\begin{array}{l}\text { Pre-treatment } \\
(\%)\end{array}$ & $\begin{array}{c}\text { Post-treatment } \\
(\%)\end{array}$ \\
\hline $\mathrm{E} / \mathrm{A}$ & $1.6 \pm 0.2$ & $0.9 \pm 2.1^{a}$ & $1.6 \pm 1.1$ & $0.9 \pm 1.1^{\mathrm{a}}$ & $1.8 \pm 1.2$ & $0.9 \pm 2.4^{b}$ \\
\hline $\begin{array}{l}\text { Isovolumetric relax- } \\
\text { ation time }\end{array}$ & $70 \pm 2.1$ & $89 \pm 1.3^{a}$ & $70 \pm 1.4$ & $90 \pm 3.1^{\mathrm{a}}$ & $68 \pm 1.2$ & $91 \pm 3.2^{b}$ \\
\hline Deceleration time & $138 \pm 0.2$ & $200 \pm 3.4^{\mathrm{a}}$ & $139 \pm 0.1$ & $202 \pm 1.2^{a}$ & $135 \pm 0.2$ & $203 \pm 3.3^{b}$ \\
\hline $\begin{array}{l}\text { Pulmonary vein Ar- } \\
\text { A }\end{array}$ & $12 \pm 3.2$ & $7 \pm 0.1^{\mathrm{a}}$ & $12 \pm 4.1$ & $7 \pm 3.1^{\mathrm{a}}$ & $14 \pm 1.2$ & $7 \pm 0.1^{b}$ \\
\hline $\mathrm{Em} / \mathrm{Am}$ & $0.9 \pm 0.9$ & $1 \pm 3.5^{\mathrm{a}}$ & $0.9 \pm 1.1$ & $1 \pm 3.7^{\mathrm{a}}$ & $09 \pm 0.1$ & $1 \pm 3.6^{a}$ \\
\hline
\end{tabular}

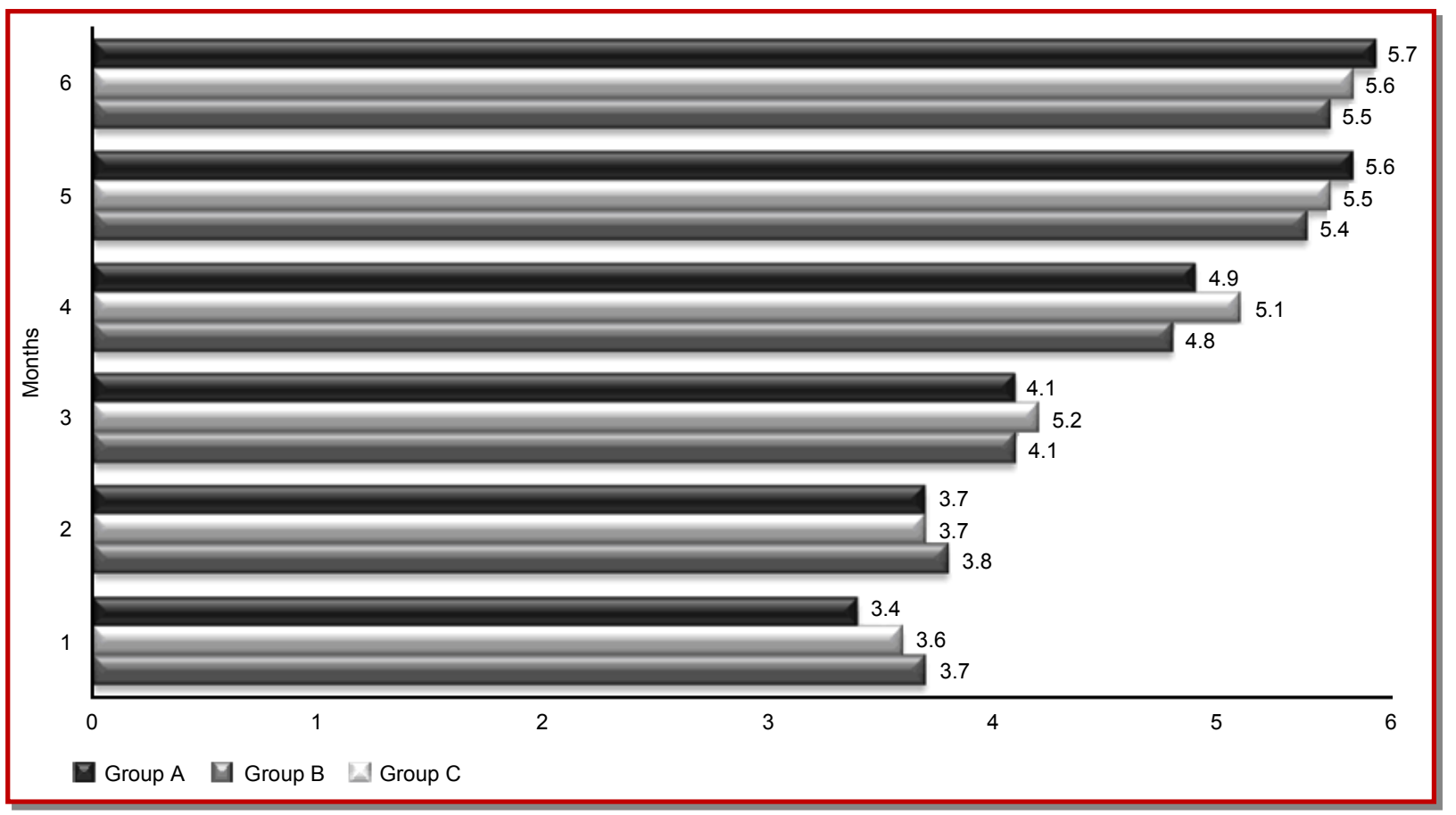

Figure 3: Comparison of the intergroup MET distribution in the pre-treatment and six month periods

Group A nebivolol-using patients and the Group B ivabradine-using patients, while a more significant improvement was observed among patients included in Group C, who used both ivabradine and nebivolol in combination.

In the MET analysis performed according to the results of the effort test, an improvement was observed in all groups that were included into the study. According to the intergroup comparison, the most significant value $(3.4 \pm 5.7 \mathrm{MET})$ was achieved among patients included in Group C (Figure 3).

In patients whose heart rate could not be reduced to the desired levels with monotherapy, a significant decrease was observed in the pre-treatment and sixth month follow-up periods with the administration of ivabra- dine and nebivolol combination (Figure 4).

Dose-related sinus bradycardia occurred in 1 (2\%) of the nebivolol-using patients included in Group A. Following a decrease in the preparations' dose, the patient's heart rate returned to normal levels.

No medication or medication dose-related side effects or drug intolerances were observed in ivabradine-using patients included in Group B. Only transient, photopsia -related ophthalmic phosphene was observed at the beginning of treatment in 2 patients. Drug use was not interrupted, and the side effect resolved on its own in 48 hours.

Headaches were observed in 2 of the nebivolol-using patients included in Group A. Symptomatic treatment 


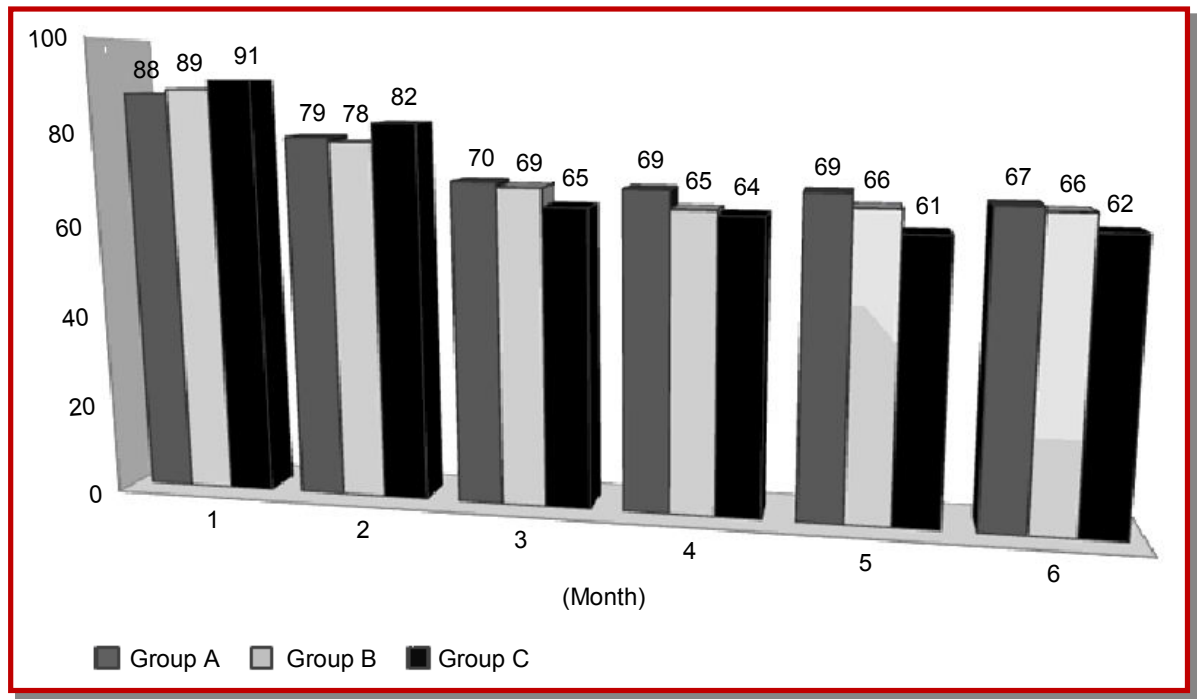

Figure 4: Intergroup comparison of pre-treatment and post-treatment heart rates

was administered.

In our study, ivabradine's effect on laboratory test values was investigated. It was accordingly observed that ivabradine did not have a negative effect on liver enzymes (ALT, AST). To assess renal function, the glomerular filtration rates (GFR) were measured in patients using both ivabradine and nebivolol. The MDRD formula was used for these measurements. The GFR values were observed at normal levels. The proteinuria, microalbuminuria and creatinine values were also assessed. No significant changes were observed in these parameters.

Pulmonary function measurements were performed on ivabradine-using patients included into Group C. The measurements were performed with spirometers and peak flow meters. In the measurements, no negative drug effects that might adversely affect the course and prognosis of COPD, bronchospasms, bronchial asthma and other respiratory system diseases were observed.

Among patients treated with monotherapy and combination therapy, comparisons were performed regarding ivabradine and nebivolol's effects on the lipid and glycemic profiles, on peripheric artery disease, and on renal functions. During treatment and at the end of the six month period, effects that concealed the symptoms of low blood sugar (fluttering, tachycardia) were observed in diabetic patients using ivabradine and nebivolol; however, these drugs did not have any negative effects on the lipid profiles. In contrast to nebivolol, erectile dysfunction was not observed among ivabradine-using patients.

Nebivolol-induced bronchospasm, erectile dysfunction, asthenia, insomnia, coronary vasoconstriction, hypotension and/or allergic reaction to active molecule were observed in 17 patients with pre-existing COPD and bronchial asthma. These were not observed in ivabra- dine-using patients.

\section{Discussion}

In our study, we have compared the effects of monoand combination therapy with ivabradine and nebivolol in stable angina pectoris patients with LVEF $\leq 40 \%$. No notable differences were observed in comparisons of nebivolol and ivabradine monotherapies' efficacy on the LVEF (nebivolol - LVEF 38-41\%; ivabradine - LVEF $37-41 \%$ ). In patients administered with a combination of ivabradine and nebivolol, it was observed that the LVEF increased from 36 to $44 \%$. In the SHIFT (Swedberg et al., 2010) and BEAUTIFUL (Kim et al., 2008) studies, Ivabradine was reported as having no adverse effects on the LVEF. The results of the BEAUTIFUL study (Kim et al., 2008) have demons-trated that ivabradine is a good choice for antianginal and antiischemic treatment, that it reduces the incidence of myocardial infarction and the need for coronary revascularization, and that it has a good tolerability profile when used in combination with other drugs. This study has also shown that ivabradine use represents advancement in the treatment of stable angina pectoris patients with heart rates of $\geq 70$ beats per minute, and that the isolated decrease in heart rate caused by ivabradine decreased the occurrence of coronary events even in patients already receiving optimal cardiovascular protective therapies. In their efficacy study on ivabradine and nebivolol combination therapy performed with 92 patients, Tatarchenko et al. (2008) observed no difference between these two drugs with regards to antianginal, antiischemic and antitachycardia efficacy.

Our study's results are in parallel with the above mentioned studies. In addition, we observed a positive increase $(36-44 \%)$ in our study on the LVEF with the ivabradine and nebivolol combination. In patients 
evaluated for antianginal, antiischemic and antitachycardia efficacy, an efficacy as significant as that of nebivolol (6 $\pm 1.6 \mathrm{mg} /$ day) was obtained with an average ivabradine dose of $12 \pm 2.5 \mathrm{mg} /$ day. When ivabradine at a dose of $10 \pm 1.9 \mathrm{mg} /$ day was combined with an average nebivolol dose of $4 \pm 1.2 \mathrm{mg} /$ day, we observed that the efficacy of both drugs further increased, while the daily dose requirement and the patients' use of nitrate and trimetazidine decreased. In our study, the ivabradine and nebivolol combination provided better results (91-62 beats/min) in patients whose heart rate could not be reduced to the desired levels by monotherapy. Even at minimal levels, the daily dose of the two preparations displayed efficacy equal to that of ivabradine and nebivolol in reducing the heart rate. According to the data of the Associate study (Tardif et al., 2009), the antianginal and antiischemic efficacy of ivabradine used in combination with beta-blocker therapy was evaluated when comparing the efficacy of ivabradine therapy. It was observed in the Associate study that patients administered with an ivabradine and beta-blocker combination therapy had better antianginal and antiischemic results than patients receiving an only beta-blocker therapy. It was also observed that the combination therapy group used less nitrate than the group using only BB. Amosova et al. (Amosova et al., 2011) have demonstrated that, for improving the exercise parameters in stable angina pectoris patients, providing combination therapy with ivabradine provided better results than doubling the dose of BB. They have also shown that ivabradine combination therapy had more than twice the efficacy of beta-blockers on the exercise parameters. There is no clear data in the literature regarding BB usage in patients with coronary artery disease and COPD (Ashrafian et al., 2005; Camsari et al., 2003). In addition to this, studies have shown that $34-36 \%$ of COPD patients also have coronary artery disease, and that this situation nearly doubles the patients' hospitalization and mortality rates (Curkendall et al., 2006; Mapel et al., 2005; Sidney et al., 2005).

In our study, the effects of the ivabradine and nebivolol mono- and combination therapies on the respiratory system were evaluated. According to our study's results, ivabradine has not demonstrated any activity or effect that might lead to pulmonary dysfunction. In their study conducted on 60 patients, Akhmetzianova et al. (2012) have shown that ivabradine had no adverse effect on the pulmonary functions of patients with COPD and pulmonary hypertension. Our results have also demonstrated that ivabradine can potentially be used as an antitachycardia agent in patients with COPD, bronchospasm and bronchial asthma. We observed that nebivolol had minimal effect on pulmonary dysfunction when used in combination with ivabradine.
In our study, we have used the results of the effort test to compare the effect of the drugs on the MET value. An increase in the average MET values of the patients was identified following the administration of nebivolol and ivabradine monotherapies. It was determined that the increase in the average MET values was more pronounced following the administration of combination therapies with these drugs. To the best of our knowledge, our study is the first to be conducted on the comparative MET values of ivabradine and nebivolol in stable angina pectoris patients with $\mathrm{LVEF} \leq 40 \%$.

The effects of the ivabradine and nebivolol mono- and combination therapies on diastolic dysfunction were evaluated in our patients. During the pre-treatment and the six month treatment periods, ivabradine's efficacy on the diastolic parameters was found to be equal to that of nebivolol. It was observed that diastolic parameters were better in patients using nebivolol and ivabradine in combination than in patients receiving monotherapy. De Luca's study (2012) conducted on 111 patients with EFs below 50\% described ivabradine's effect in improving diastolic parameters on its own. Our results support the findings of the above mentioned study. In addition to this, our results also indicate that the combination of ivabradine with nebivolol further increases its efficacy on the diastolic parameters.

In the quality of life assessment, it was observed that the improvement in patients administered with the ivabradine and nebivolol combination was more pronounced and significant. To the best of our knowledge, our study is the first comparative study to be conducted with the SAQ questionnaire on ivabradine and nebivolol-using stable angina pectoris patients with a LVEF $\leq 40 \%$.

In our study, we have compared the rates of hospitalization observed with mono- and combination therapies of ivabradine and nebivolol in stable angina pectoris patients with $\mathrm{LVEF} \leq 40 \%$. Among patients included into Group A and B, no hospitalization was observed by the end of the fifth month. While no significant differences were noted between these two groups (Group A and B), a more significant change was observed in Group C patients, who were administered with the ivabradine and nebivolol combination. Our study supports the findings of the SHIFT (Swedberg et al., 2010) and BEAUTIFUL (Kim et al., 2008) studies.

In our study, both the mono- and combined therapies of ivabradine and nebivolol have not adversely affected the lipid values and liver enzymes of the patients. However, as ivabradine and nebivolol tend to conceal the symptoms of low blood sugar (fluttering, tachycardia), they should be used cautiously in diabetic patients.

We have determined that the frequency of side effects observed in ivabradine monotherapy (such as dose 
intolerance-related bradycardia and photopsia-related ophthalmic phosphene) as well as the frequency of side effects that may develop as a result of nebivolol monotherapy (such as bronchial asthma, bronchospasm in COPD patients, erectile dysfunction, asthenia, insomnia, hypotension, sinus bradycardia and headache) decreased or remained at minimal levels when a low dose combination of these two drugs was used. We believe that providing a combination of nebivolol and ivabradine at lower doses instead of using maximum doses of the two drugs in monotherapy would provide a safer approach with regards to the side effect profile.

\section{Conclusion}

Ivabradine can be considered as an alternative antiischemic and antianginal agent, as well as an agent for reducing cardiac rhythm, for left ventricular dysfunction patients with sinus rhythm who have developed an intolerance to nebivolol, and for whom nebivolol on its own is insufficient for treatment. Among patients in which effective treatment could not be achieved at maximum nebivolol doses, more effective results were obtained in our study with the combination of ivabradine and nebivolol at lower doses.

\section{References}

Akhmetzianova ÉKh, Gaĭnitdinova VV, Bakirov AB, Bogoroditskaia OA, Timershina IR. Effect of ivabradine on pulmonary hypertension in chronic obstructive pulmonary disease. Kardiologiia 2012; 52: 41-46.

Amosova E, Andrejev E, Zaderey I, et al. Efficacy of ivabradine in combination with beta-blocker versus uptitration of betablocker in patients with stable angina. Cardiovasc Drugs Ther. 2011; 25: 531-37.

Arrebola-Moreno A, Dungu J, Kaski JC. Treatment strategies for chronic stable angina. Expert Opin Pharmacother. 2011; 12: $2833-44$.

Ashrafian H, Violaris AG. Beta-blocker therapy of cardiovascular diseases in patients with bronchial asthma or COPD: The pro viewpoint. Prim Care Respir J. 2005; 14: 23641.

Borer JS, Böhm M, Ford I, et al. Effect of ivabradine on recurrent hospitalization for worsening heart failure in patients with chronic systolic heart failure: The SHIFT
Study. Eur Heart J. 2012; 33: 2813-20.

Camsari A, Arikan S, Avan C, et al. Metoprolol, a beta-1 selective blocker, can be used safely in coronary artery disease patients with chronic obstructive pulmonary disease. Heart Vessels. 2003; 18: 188-92.

Curkendall SM, De Luise C, Jones JK, et al. Cardiovascular disease in patients with chronic obstructive pulmonary disease. Ann Epidemiol. 2006; 16: 63-70.

De Luca G. İvabradine and diastolic heart failure. Am Coll Cardiol. 2012; 59: E1009.

Fox K, Garcia MA, Ardissino D, et al. Guidelines on the management of stable angina pectoris: Executive summary: The task force on the management of stable angina pectoris of the European Society of Cardiology. Eur Heart J. 2006; 27: 1341-81.

Fraker TD Jr, Fihn SD, Gibbons RJ, et al. 2007 chronic angina focused update of the ACC/AHA 2002 guidelines for the management of patients with chronic stable angina: A report of the American College of Cardiology/American Heart Association Task Force on Practice Guidelines Writing Group to develop the focused update of the 2002 guidelines for the management of patients with chronic stable angina. J Am Coll Cardiol. 2007; 50: 2264-74.

Kim Fox, Ian Ford, P Gabriel Steg, et al. Ivabradine for patients with stable coronary artery disease and left-ventricular systolic dysfunction (BEAUTIFUL): A randomised, doubleblind, placebo-controlled trial. Lancet 2008; 372: 807-16.

Mapel DW, Dedrick D, Davis K, et al. Trends and cardiovascular comorbidities of COPD patients in the Veterans Administration Medical System, 1991-1999. COPD. 2005; 2: 35-41.

Sidney S, Sorel M, Quesenberry CP, et al. COPD and incident cardiovascular disease hospitalizations and mortality: Kaiser Permanente Medical Care Program. Chest 2005; 128: 2068-75.

Swedberg K, Komajda M, et al. Ivabradine and outcomes in chronic heart failure (SHIFT): A randomised placebocontrolled study. Lancet 2010; 376: 875-85.

Tardif JC, Ponikowski P, Kahan T, ASSOCIATE Study Investigators. Efficacy of the I(f) current inhibitor ivabradine in patients with chronic stable angina receiving beta-blocker therapy: A 4-month, randomized, placebo-controlled trial. Eur Heart J. 2009; 30: 540-48.

Tatarchenko IP, Pozdniakova NV, Biriuchenko MV, et al. Clinical efficacy of ivabradin and nebivolol addition in combined treatment of ischemic heart disease patients with left ventricular dysfunction. J Ter Arkh. 2008; 80: 40-44. 